\title{
DTC Switching Strategy for Open-end Winding of Induction Machines Fed by a Dual-output Indirect Matrix Converter
}

\author{
Abdelkader Beladel ${ }^{1 *}$, Abdellah Kouzou $^{1}$, Mohamed Elbar $^{1}$, Ahmed Hafaifa $^{1}$ \\ ${ }^{1}$ Applied Automation and Industrial Diagnostics Laboratory (LAADI), Faculty of Sciences and Technology, Ziane Achour University, \\ P. O. B. 3117, Djelfa 17000, Algeria \\ * Corresponding author, e-mail: a.beladel@mail.univ-djelfa.dz
}

Received: 28 November 2020, Accepted: 12 January 2021, Published online: 07 June 2021

\begin{abstract}
This paper deals with the Direct Torque Control (DTC) of Dual Indirect Matrix Converter (DIMC) feeding an open-end winding threephase Induction Motor (IM). Indeed, the open-end winding topology allows overcoming the main problem of Common-Mode Voltage (CMV) which is responsible of presence of stresses in the motor winding in classical topologies, controlling separately the winding of the three-phases, reducing the voltage stress of the power electronics switches and to decreasing the voltage and current harmonics in each phase. The proposed Dual-output Indirect Matrix Converter generates 18 active voltage space vectors. Whereas, in the proposed algorithm presented in this paper to ensure the control of the proposed topology it is implemented only with two null vectors and six active voltage vectors for each output. It is based on same idea of the space vector pulse width modulation that is applied separately for both converters to ensure the control of their output voltages. Indeed, to ensure the required voltage at each winding the output voltage of the first matrix converter are generated normally and output voltage of the second matrix converter are generated with $180^{\circ}$ phase shift. The obtained simulation results prove clearly the overall performance of the control of the studied drive system based on the proposed topology and its control algorithm which may be extended to other drive system application, especially in industrial application where more improved performances are required.
\end{abstract}

Keywords

Direct Torque Control (DTC), Open-End Winding Induction Motor (OEWIM), Indirect Matrix Converter (IMC), Common-Mode Voltage (CMV)

\section{Introduction}

Recently many topologies of have been proposed to ensure driving the three-phase Induction Motor (IM) and to provide high performances compared to the well know conventional topologies. Among these topologies are the multi-level topologies, which allow obtaining better output voltage and current qualities that lead to better performance and high efficiency. However these topologies require a bulky DC link between the AC-DC converter and the DC-AC converter similarly to the conventional ones. On the other side the circuit control are more complicated and more components are required such as the clamped diodes, the flying capacitors or more separated number of DC sources following the used multi-level topology. In this paper the Open-End Winding Induction Motor (OEWIM) powered by a dual AC-AC converter is presented, firstly the bulky DC link is removed as an Indirect Matrix Converter (IMC) is used, secondly the application of a dual IMC allows obtaining a multi-level voltage at the terminal of each stator winding phase separately, thirdly the CommonMode Voltage (CMV) is usually presenting a very delicate challenging problem in stator star connection fed by conventional inverter which induces shaft voltage leading to the circulation of bearing current causing to premature bearing and motor failures over time. These problems can be solved by using the OEWIM presented in this paper $[1,2]$.

The Indirect Matrix Converter (IMC) is an AC-AC type converter. It is basically composed of a variety of bidirectional switches that are used to ensure the transfer of the power supply to the load with controlled frequency and voltage magnitude without using any DC connection or bulky energy storage components $[3,4]$. Indeed, the absence of large energy storage elements in the DC bus such as capacitors is the first real preference of such topology over the ordinary rectifier-inverter based topologies that have been 
used along the last decades in most of the industrial applications. Hence this converter topology allows obtaining less size and weight compared the conventional $[3,5,6]$. On the other side, the IMC can provide from the available AC three-phase power supply, AC output voltages with desired amplitude and frequency, theoretically with unlimited number of output phases. Based on the control technique used, the harmonic content can be reduced in the output side of the IMC, where the input power factor can be also improved [5-7]. However, the harmonics content in the input side current is presenting a big challenge in the IMC topology, where the simple solution to handle this issue can be achieved by using an input LC filter as shown in Fig. 1.

In this paper the IMC topology is used to power an Open-End Winding Induction Motor (OEWIM) which can be obtained by opening the neutral or the star point of the stator windings of the conventional three-phase Induction Motor based on the main idea as shown in Fig. 2. However, the OEWIM topology needs to be fed by a Dual Indirect Matrix Converter (DIMC) as shown in Fig. 2. Indeed, this topology offers several advantages in comparison with their counterpart of the conventional star stator winding of Induction Motor [3].

The main characteristics of the OEWIM powered by IMC can be summarized as follows [3-8]:

- each matrix converter is rated at $50 \%$ of the machine power, because the machine is powered by both ends of the windings;

- each phase of the stator currents can be powered separately and checked individually.

- ability to have doubled effective switching frequency (depending on the modulation strategy);

- allows obtaining multi-level voltage that is applied to each phase winding such as for similar output voltages with $(n)$ levels in both side the resulting winding phase voltage will be $(2 n-1)$ for asymmetric winding phase voltage such as $(n)$ levels and $(m)$ levels for the both IMC respectively, the resulting winding phase voltage will be (n.m) levels;

- reliability against the partial interruption of the three-phase input power supply, where the output three-phase voltages system is kept following the desired amplitude and frequency and hence the motor operation will not be interrupted;

- the ability of eliminating the common mode voltage compared to the star winding connection.

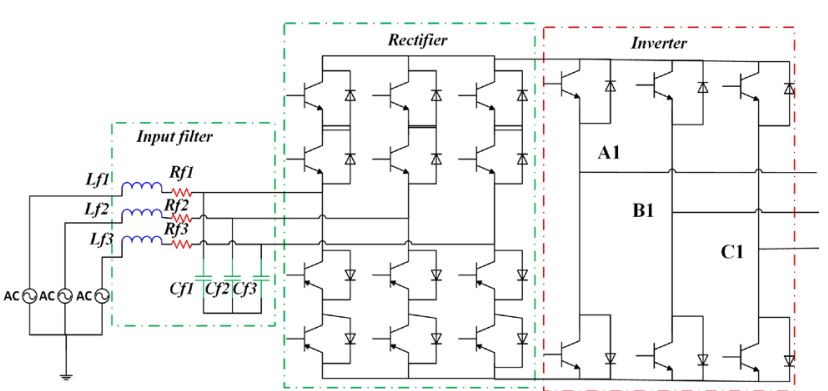

Fig. 1 Indirect Matrix Converter (IMC)

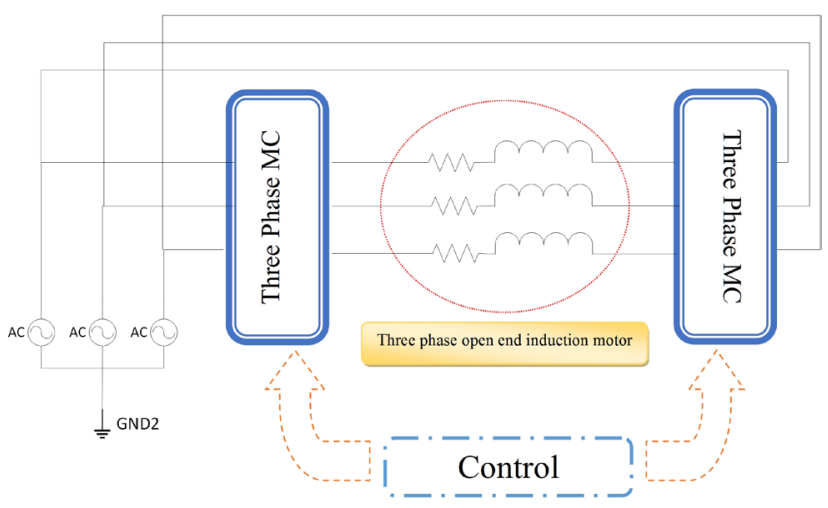

Fig. 2 Three phase open-end Induction Motor drive system

In the present paper the Direct Torque Control (DTC) technique is applied on the Dual Indirect Matrix Converter (DIMC) feeding a three-phase open winding induction machine. The main objective is to improve the performance of the IM related to practical issues such as the current quality, the minimization of the voltage stress at the switches, ensuring more freedom degree by powering the phase windings independently, eliminating of the Common-Mode Voltage and achieving more control flexibility. This resulting in improving the operation reliability of three-phase induction machines used in industrial applications where the maintenance of such machines is more delicate or even difficult to be done instantaneously.

\section{Principal of dual converter topology powering an open-end winding induction machine}

There are different configurations of power converters that can be used to supply the open-end winding induction machine. In this paper the Dual Indirect Matrix Converter topology is used where the main aim is to overcome some drawbacks that have been faced within the classical topologies and on the other hand to improve the performance and the reliability of the proposed converter-machine system. Virtually the Indirect Matrix Converter can 
be seen and managed as the classical association of rectifier inverter circuits without DC link storage elements. The overall circuit of the studied topology configuration with the OEWIM is shown in Fig. 3. In this topology each IMC of the dual topology feeds one side of the three-phase stator winding terminals, however the both IMCs are supplied from the same three-phase power supply with fixed frequency and voltage magnitude. It means that the virtual rectifier which is supplied from the three-phase power supply is common to the both virtual inverters feeding the two terminals set of the induction machine $[3,9,10]$. According to the proposed topology, the rectifier operation has to fulfill three objectives; ensuring a maximum output positive voltage at the virtual DC link at each sampling period, operating with unity power factor at the input and minimizing the input current harmonics.

The output of the presented topology is composed of two DC-AC converters, which are connected to both sides of the stator winding terminals respectively, presenting two virtual inverters. These inverters should be controlled to satisfy the main goals of reducing the CommonMode Voltage in comparison with the classical topologies, ensuring a variable output voltage frequency and magnitude and minimizing the output voltage harmonics components [11-13].

Each inverter works independently and produces eight space-vector voltages. As a result, it was found that there are 64 voltage vector combinations between the two inverters. In the OEWIM topology the stator windings terminals of each phase are connected to the two inverter where each phase winding are seen to be powered separately from both terminals by the corresponding output phase of the two inverters [12-14].

\subsection{Modeling of the Input Stage of IMC}

At the rectifier stage as shown in Fig. 4, the two zerovector are eliminated and the output voltage is synthetized during each switching sequence by only two adjacent vectors (line-to-line voltages) [10]. The main role of this stage is to power the DC-link to ensure providing the required maximum average $\mathrm{DC}$-link voltage which allows obtaining the required voltage ratio between the DC-link value and the desired output voltage maximum value. In this paper the Space Vector Modulation (SVM) technique is used to control the rectifier stage shown in Fig. 4 for obtaining a maximum positive voltage at the virtual DC link (Table 1) [1, 3]. The duty cycles for this step are expressed as follows:

$d_{\gamma}^{R}=\frac{d_{\gamma}}{d_{\gamma}+d_{\delta}}, d_{\delta}^{R}=\frac{d_{\delta}}{d_{\gamma}+d_{\delta}}$,

where:

$d_{\gamma}=\sin \left(\pi / 3-\theta_{r e f, i}\right)$ and $d_{\delta}=\sin \left(\theta_{r e f, i}\right)$

$\theta_{\text {ref }}$ is angle of the voltage reference vector.

The DC link voltage shown in Fig. 5, it can be noted that for the DC link voltage has less ripple.

\subsection{Modeling of the output stage of the IMC}

Several approaches have been proposed and applied for the selection of the adequate voltage space vectors used for control [15-17].

For the topology shown in Fig. 3, the goal of the modulation strategy for the output stages is to reduce $v_{c m}$, while still providing the desired machine phase voltages. The voltage vectors for controlling the inverter 1 are shown in Table 1; the same voltage vectors are valid for inverter 2.

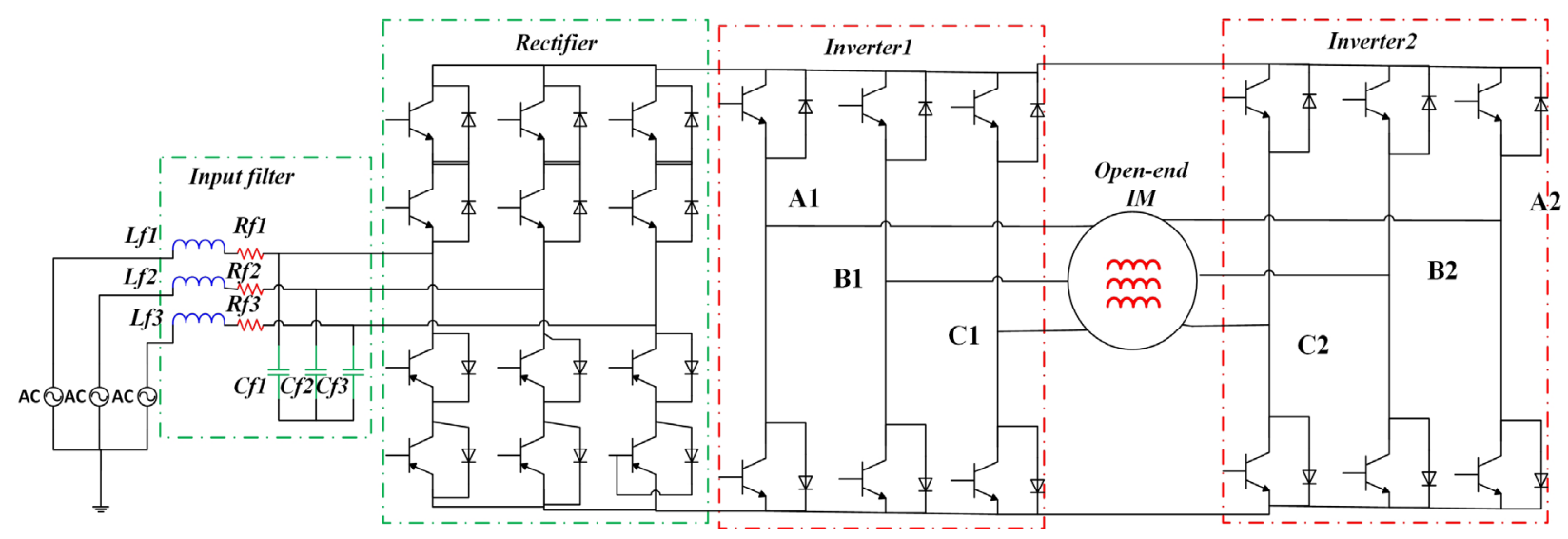

Fig. 3 Indirect Matrix Converter with one input and two output stages feeding an open-end Induction Motor 


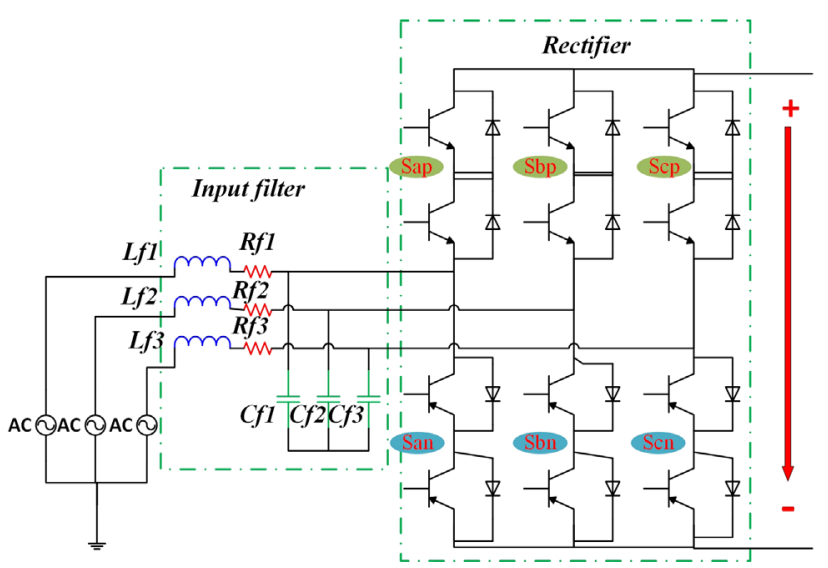

Fig. 4 Basic topology of the input stage

Table 1 Duty cycle and switching pattern of the rectifier

\begin{tabular}{llccccccc}
\hline$\theta$ & $-\frac{\pi}{6} \sim \frac{\pi}{6}$ & & $\frac{\pi}{6} \sim \frac{\pi}{2}$ & & \multicolumn{2}{c}{$\frac{\pi}{2} \sim \frac{5 \pi}{6}$} \\
\hline Duty Cycle & $d_{1}$ & $d_{2}$ & $d_{1}$ & $d_{2}$ & $d_{1}$ & $d_{2}$ \\
Values & $d_{b a}$ & $d_{c a}$ & $d_{b c}$ & $d_{a c}$ & $d_{c b}$ & $d_{a b}$ \\
Conducting & & $S_{a b}$ & & & $S_{c n}$ & & & $S_{b p}$ \\
Switches & $S_{b n}$ & $S_{c n}$ & $S_{b p}$ & $S_{a b}$ & $S_{c n}$ & $S_{a n}$ \\
\hline
\end{tabular}

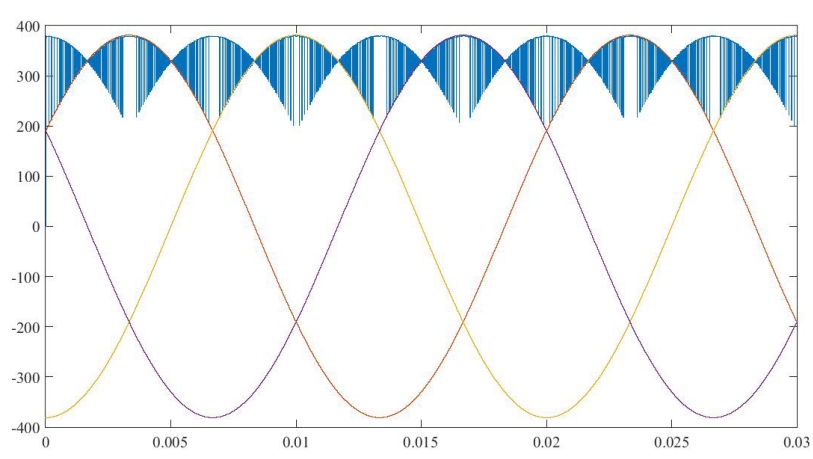

Fig. 5 The maximum DC-link voltage at the output side of the rectifier stage

Considering $V_{1}^{1}-V_{8}^{1}$ as the voltage vectors for inverter 1 , then the state of the switches for inverters is given in Table 2.

As it was mentioned that virtual inverter of the IMC can produce eight space voltage vectors as shown in Fig. 6.

\begin{tabular}{lc}
\multicolumn{2}{c}{ Table 2 Voltage vectors for inverter } \\
\hline$V_{1}^{1}$ & {$\left[\begin{array}{lll}1 & 0 & 0\end{array}\right]$} \\
\hline$V_{2}^{1}$ & {$\left[\begin{array}{lll}1 & 1 & 0\end{array}\right]$} \\
$V_{3}{ }^{1}$ & {$\left[\begin{array}{lll}0 & 1 & 0\end{array}\right]$} \\
$V_{4}^{1}$ & {$\left[\begin{array}{lll}0 & 1 & 1\end{array}\right]$} \\
$V_{5}{ }^{1}$ & {$\left[\begin{array}{lll}0 & 0 & 1\end{array}\right]$} \\
$V_{6}{ }^{1}$ & {$\left[\begin{array}{lll}1 & 0 & 1\end{array}\right]$} \\
$V_{7}{ }^{1}$ & {$\left[\begin{array}{lll}1 & 1 & 1\end{array}\right]$} \\
$V_{8}{ }^{1}$ & {$\left[\begin{array}{lll}0 & 0 & 0\end{array}\right]$} \\
\hline
\end{tabular}

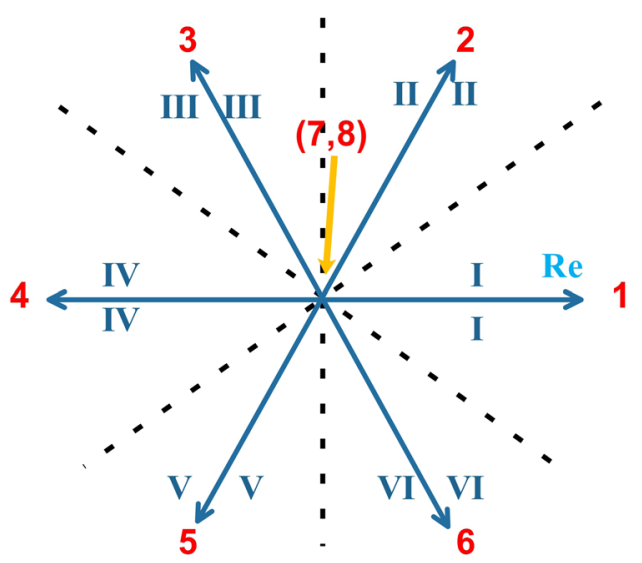

Fig. 6 Space vector locations for maximum DC voltage

\subsubsection{Common-Mode Voltage (CMV)}

It is well know that the Common-Mode Voltage cause currents flow through the stray capacitances in the motor when supplying induction machines by the usual inverter topologies. As this current find their way through the conductive parts or components of the motor to the grounded stator case, especially the bearings and shaft, this forms the so-called bearing currents [15-19]. In a dual inverter system feeding an open-end load, the CMV can be calculated as follows:

$v_{c m}=\frac{1}{6}\left(v_{A 1 G}+v_{B 1 G}+v_{C 1 G}+v_{A 2 G}+v_{B 2 G}+v_{C 2 G}\right)$,

where $v_{A 1 G}, v_{B 1 G}, v_{C 1 G}, v_{A 2 G}, v_{B 2 G}, v_{C 2 G}$ are the output terminal voltages of the both virtual inverters with respect to the power supply grounded to neutral point as shown in Fig. 2.

For the reference neutral point "0" in Fig. 2, the equation for the CMV can be rewritten as follows:

$v_{c m}=v_{C m 0}+v_{0 G}$,

where

$v_{c m 0}=\frac{1}{6}\left(v_{A 10}+v_{B 10}+v_{C 10}+v_{A 20}+v_{B 20}+v_{C 20}\right)$

$v_{c m 0}$ is the Common-Mode Voltage referred to the reference neutral point " 0 " $v_{0 G}$ is the voltage between the reference neutral point " 0 " and the power supply grounded neutral point and it can be calculated as follow:

$v_{0 G}=\frac{1}{2}\left[s_{a p n} V_{r a}+s_{b p n} V_{r b}+s_{c p n} V_{r c}\right]$,

where:

$s_{a p n}=\frac{1}{2}\left(s_{a p}+s_{a n}\right)$,

$s_{b p n}=\frac{1}{2}\left(s_{b p}+s_{b n}\right)$,

$s_{c p n}=\frac{1}{2}\left(s_{c p}+s_{c n}\right)$. 
Where $s_{i p}, s_{i n}$ are the upper and lower switching state of the rectifier stage, respectively with $i=a, b, c$ and $V_{r k}$ with $k=a, b, c$ is the input phase voltage.

\section{Direct Torque Control of open-end winding induction motor}

Several approaches have been proposed and applied for the selection of the adequate voltage space vectors used for the Direct Torque Control [20-22]. Fig. 6 shows the possible space vectors of the inverter output phase voltages, which divide the space to six sectors. All the sectors possess the same angle of $\pi / 3$ radian and are distributed equally along the plan space where each sector is delimited by two voltage space vector. If the stator flux space vector is located in the $k^{\text {th }}$ sector, that $k=1,2, \ldots 6$, its magnitude can be increased using the voltage vectors $k, k+1, k-1$ and can be decreased using the voltage vectors $k+2, k-2, k+3$, [13]. However, the selected voltage vector will also affect the output torque of the Induction Motor. From Table 2, the states of the inverter switches are defined by a set of three binary signals based on the six possible active space vectors, the transition from one state to another requires only a change of one switch state among switches at the three-inverter legs. Whereas, only one vector among the three vectors will be applied depending on the torque and the flux errors [16].

As it was mentioned that virtual inverter of the IMC can produce eight space voltage vectors as shown in Fig. 6 and are given in Table 3. This means that 64 combinations of space vectors can be obtained between the two virtual inverters which is similar to total number of the threelevel Neutral Point Clamped (NPC) inverter [10]. Hence the voltage applied to the OEWIM is seen as a three-level voltage power supply.

Table 3 Phase to neutral voltages of three-phase voltage source inverter

\begin{tabular}{lccccc}
\hline $\begin{array}{l}\text { Switching } \\
\text { state }\end{array}$ & $\begin{array}{c}\text { Switches } \\
\text { on }\end{array}$ & $\begin{array}{c}\text { Phase } \\
\text { voltage }\end{array}$ & $\begin{array}{c}\text { Phase } \\
\text { voltage }\end{array}$ & $\begin{array}{c}\text { Phase } \\
\text { voltage }\end{array}$ & $\begin{array}{c}\text { Space } \\
\text { vector }\end{array}$ \\
\hline 1 & $1,4,6$ & $(2 / 3) V_{D C}$ & $-(1 / 3) V_{D C}$ & $-(1 / 3) V_{D C}$ & $\underline{v}_{1 p h}(100)$ \\
2 & $1,3,6$ & $(1 / 3) V_{D C}$ & $(1 / 3) V_{D C}$ & $-(2 / 3) V_{D C}$ & $\underline{v}_{2 p h}(110)$ \\
3 & $2,3,6$ & $-(1 / 3) V_{D C}$ & $(2 / 3) V_{D C}$ & $(2 / 3) V_{D C}$ & $\underline{v}_{3 p h}(010)$ \\
4 & $2,3,5$ & $-(2 / 3) V_{D C}$ & $(1 / 3) V_{D C}$ & $(1 / 3) V_{D C}$ & $\underline{v}_{4 p h}(011)$ \\
5 & $2,4,5$ & $-(1 / 3) V_{D C}$ & $-(1 / 3) V_{D C}$ & $(2 / 3) V_{D C}$ & $\underline{v}_{5 p h}(001)$ \\
6 & $1,4,5$ & $(1 / 3) V_{D C}$ & $-(2 / 3) V_{D C}$ & $(1 / 3) V_{D C}$ & $\underline{v}_{6 p h}(101)$ \\
7 & $1,3,5$ & 0 & 0 & 0 & $\underline{v}_{7 p h}(000)$ \\
8 & $2,4,5$ & 0 & 0 & 0 & $\underline{v}_{8 p h}(111)$ \\
\hline
\end{tabular}

The principle idea of the DTC is to select the best voltage vector which keeps the flux and the torque within a defined permitted bandwidth with least inflation [23, 24]. The block diagram of the DTC scheme is shown in Fig. 7.

The stator flux vector can be calculated using the measured current and voltage.

$$
\begin{aligned}
& \frac{d \psi_{s}}{d t}=U_{s}-R_{s} I_{s} \\
& \psi_{d s}=\int\left(U_{d s}-R_{s} I_{d s}\right) \mathrm{d} t \\
& \psi_{q s}=\int\left(U_{q s}-R_{s} I_{q s}\right) \mathrm{d} t
\end{aligned}
$$

The electromagnetic torque developed by the IM is expressed as follows:

$$
T_{e m}=\frac{3}{2} p\left(\psi_{d s} I_{q s}-\psi_{q s} I_{d s}\right),
$$

where $L_{S}$ is the stator self-inductance; $L_{r}$ is the rotor self-inductance in the stator reference frame; $p$ is the number of pole pairs. $\psi_{d s}$ and $\psi_{q s}$ are the stator fluxes following the $d$ and $q$ axis, respectively and $\theta$ is the angle between the two fluxes. The estimated flux and torque are then compared with their reference values; the result values from these comparisons are introduced into the corresponding hysteresis comparators respectively. Furthermore, outputs of the comparators with the position of the stator flux are used as inputs for the switching table. Finally, based on the data from the switching table, the control signals of the switches for both virtual inverters are obtained. The main aim is to ensure that the flux and the torque remain within their desired tolerance band and rejoin promptly to their reference trajectories [24, 25].

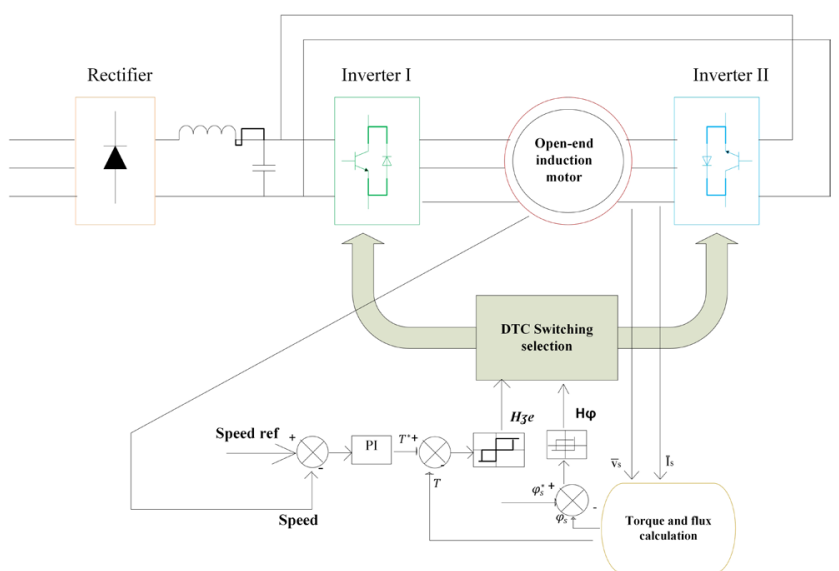

Fig. 7 DTC scheme with speed regulation 


\section{Simulation results and discussions}

The simulation model of the overall system which presents the open-end winding induction machine fed by a Dual-output Indirect Matrix Converter has been built in Matlab/Simulink environment. The model is mainly based on three main parts namely, the $d-q$ Induction Motor, the Dual Indirect Matrix Converter and the Direct Torque Control block. The output voltage is characterized by the magnitude and the frequency of $350 \mathrm{~V}$ and $50 \mathrm{~Hz}$, respectively. The parameters of the induction machine and the input voltage are given in Table 4. On the other hand, due to the distortion which can occur in the input current and to prevent the propagation of this type of harmonic pollution towards the source, an input LC filter is inserted in the input side as shown in Fig. 2.

Table 4 Simulation parameters

\begin{tabular}{lcc}
\hline$V_{s}$ & Input voltage & $350 \mathrm{~V}$ \\
$f_{s}$ & Input frequency & $50 \mathrm{~Hz}$ \\
$f_{o}$ & Output frequency & $50 \mathrm{~Hz}$ \\
$L_{f}$ & Filter inductance & $0.03 \mathrm{H}$ \\
$R_{f}$ & Filter Resistance & $0.5 \Omega$ \\
$C_{f}$ & Filter Capacitance & $25 \mathrm{e}-6 \mathrm{~F}$ \\
$R_{s}$ & Stator resistance & $4.85 \Omega$ \\
$R_{r}$ & Rotor resistance & $3.81 \Omega$ \\
$L_{s}$ & Stator inductance & 0.274 \\
$L_{r}$ & Rotor inductance & $0.274 \mathrm{H}$ \\
$L_{m}$ & Mutual inductance & $0.258 \mathrm{H}$ \\
\hline
\end{tabular}

Simulation results for the output voltages of both IMCs, $V_{m c 1}$ and $V_{m c 2}$ for phase "A" are presented in Fig. 8 and the input currents are presented in Fig. 9. Figs. 10 and 11 show the Common-Mode Voltages $V_{C m 0}$ referred to the reference neutral point and the voltage $v_{0 G}$ which present the difference of potential between the reference neutral point and the power supply grounded neutral point as defined in Eqs. (3) and (4). The stator flux trajectory in the $d-q$ frame is presented in Fig. 12, it is clear that the both components of the flux following $d$ and $q$ axis are shifted by $\pi / 2$ at each time step due to the circular form of the flux. Furthermore, it is obvious that this trajectory has less ripples which is explained by the tight band of this trajectory, this proves clearly the high performance of the application of the DTC control technique to the dual IMC feeding an Open-End Winding IM. Fig. 13 shows stator flux in $d$-axis and stator flux in $q$-axis separately which proved the aforementioned explanation depicted from the flux trajectory. Fig. 14 shows the waveforms of the power supply phase voltage, the input phase current of IMC and the motor current. It is obvious that the input current of the IMC is nearly sinusoidal, but it contains some harmonics components due to the switching operation dynamics and to the switching frequency. This current is in phase with the power supply voltage which means that the input power factor is greatly improved and its value is near to unity. On the other side, the current absorbed by the IM which is the same current supplied at the output side of the IMCs has a frequency of $23 \mathrm{~Hz}$ with

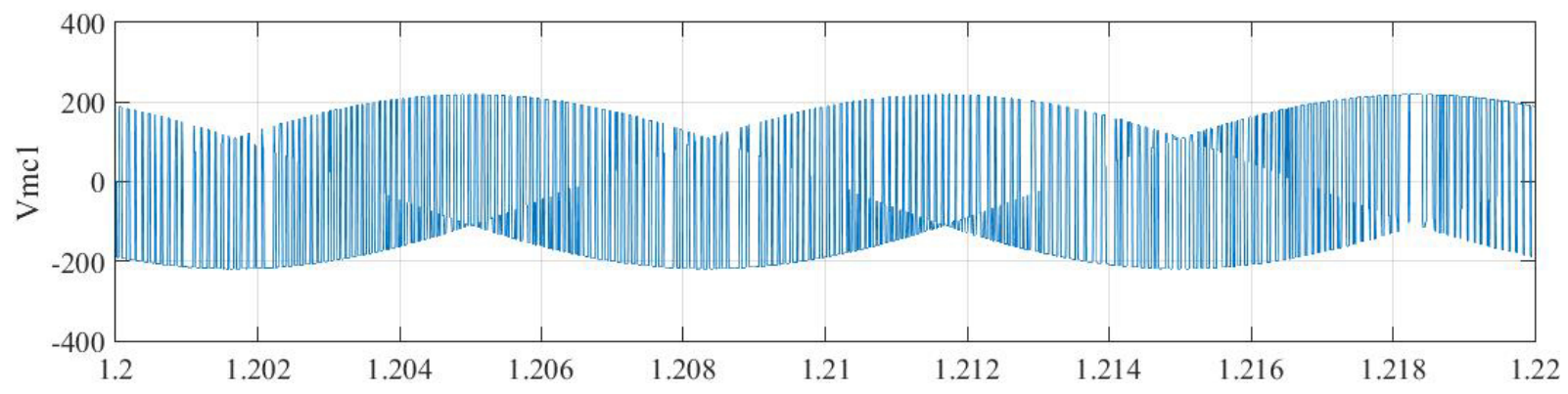

(a)

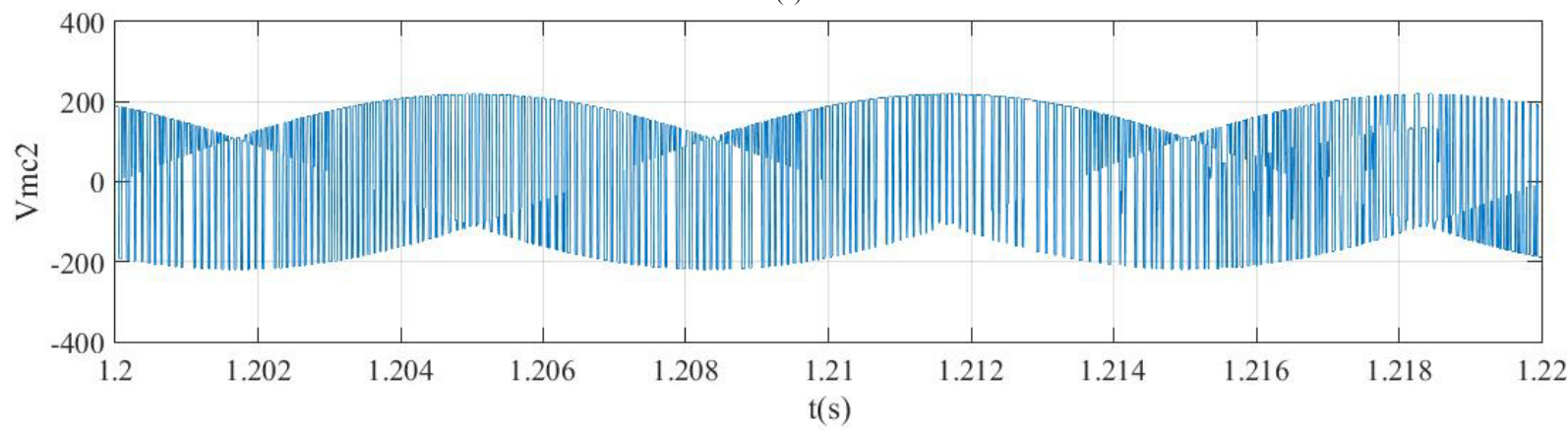

(b)

Fig. 8 Output phase voltages (a) first matrix converter, (b) second matrix converter) 


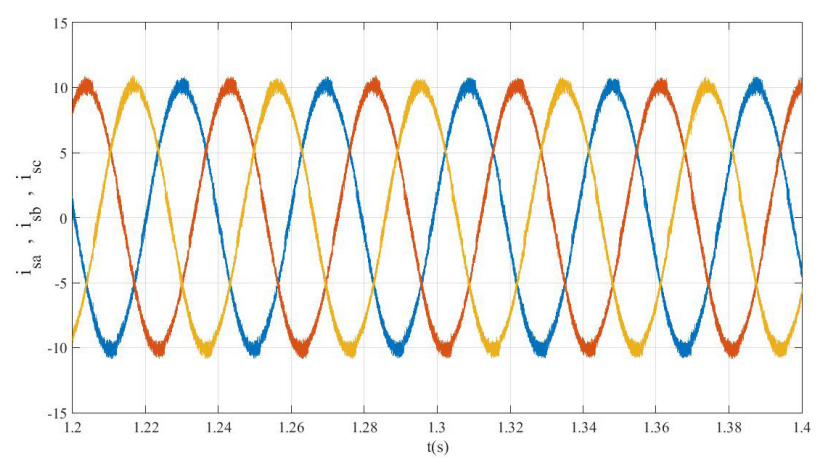

Fig. 9 Three-phases stator currents

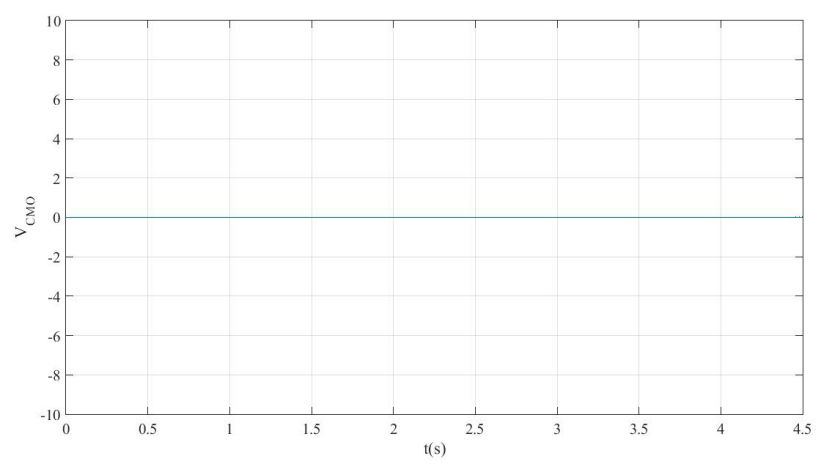

Fig. 10 Common-Mode Voltage, VOG

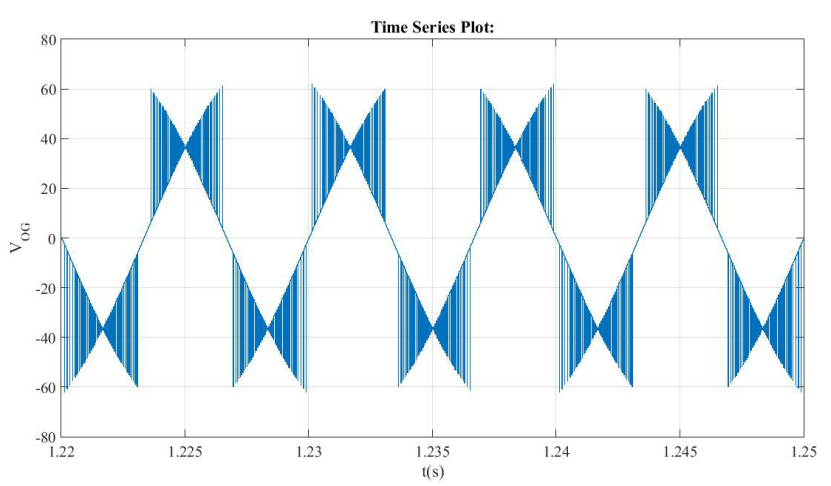

Fig 11 Common-Mode Voltage, VCMO

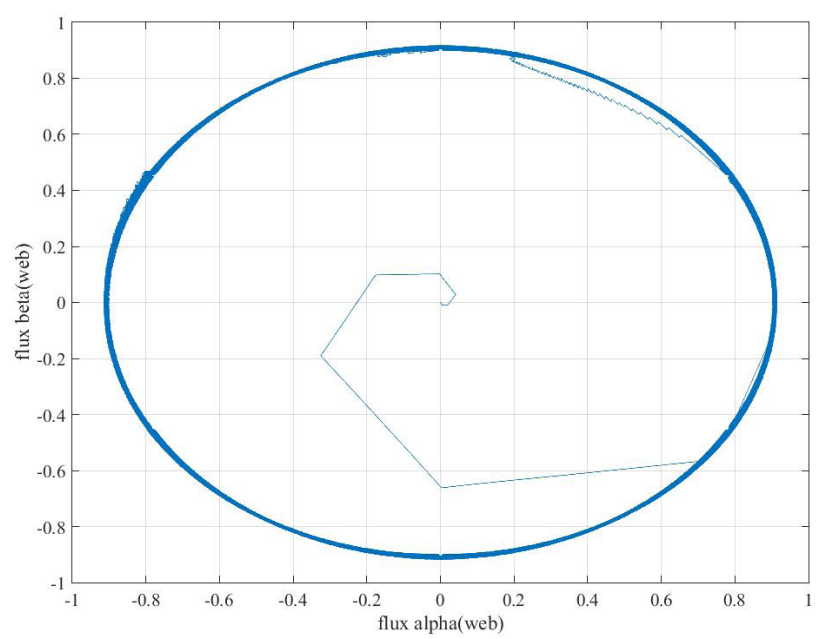

Fig. 12 Flux circular trajectory of DTC based on IMC with optimum switching sinusoidal waveform which means that the harmonics content is nearly null. This is due to the low-pass filter behavior of the IM windings and therefore, there is no need for inserting extra filters at the output side of the IMCs.

Fig. 15 shows the behavior of the speed Induction Motor at starting up and speed reversal modes. At start-up the machine speed reaches to the reference speed $(150 \mathrm{rad} / \mathrm{s})$ within a very short time, then the motor is loaded at the instant of $0.5 \mathrm{~s}$ where a zoom is presented to demonstrate the performance of the speed motor in more detail. After loading the machine, the speed drops and due to the closed loop control it rejoins the reference speed within a negligible time. At $t=1.5 \mathrm{~s}$, the load is removed where it can be seen clearly in the zoom window that the motor speed

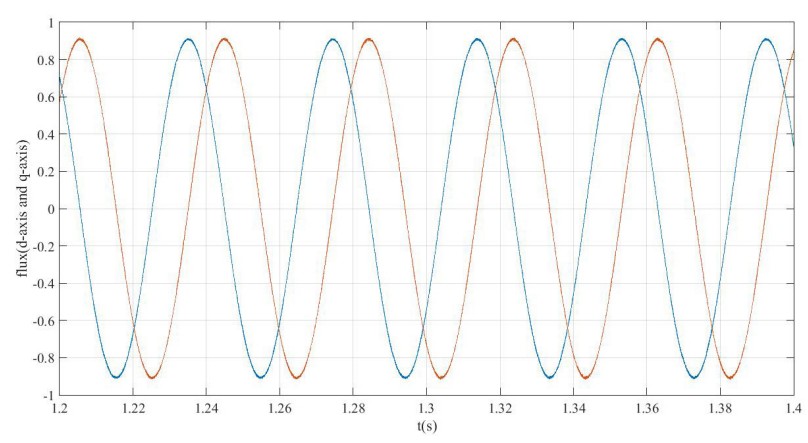

Fig. 13 Stator $d$-axis flux and $q$-axis flux

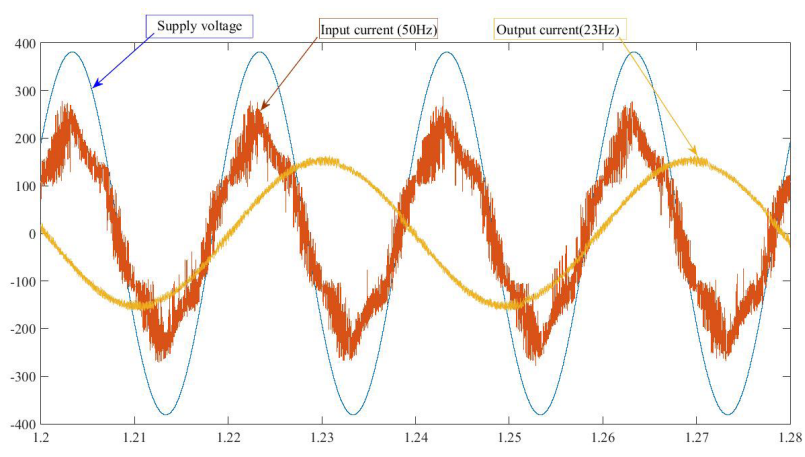

Fig. 14 Waveforms of the Induction Motor in steady-state operation showing asynchronous operation of the matrix converter

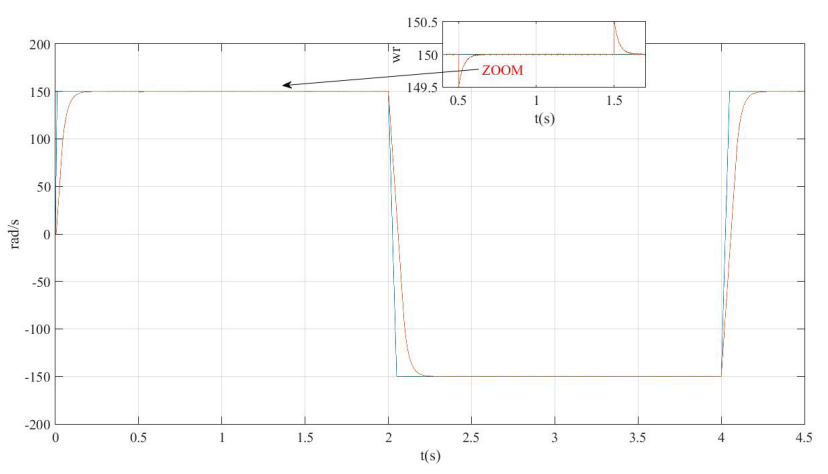

Fig. 15 Speed of the motor 
increases within a very short time and settles down at the reference speed which proved the high dynamic of the used controller. It can be note also that the torque developed by the IM increases during the application of the load to overcome the resistive torque imposed by the load application as shown in Fig. 16. At $t=2 \mathrm{~s}$ the reference speed is reversed to $-150 \mathrm{rad} / \mathrm{s}$ where one again the motor rejoins its reference speed very quickly as it can be seen in Fig. 15. The developed torque responses dynamically and accurately to these changes following the increase or the decrease of the applied load as shown in Fig. 16. This high dynamic response to the speed change and even the load change proves the high performance quality of the proposed control and the topology of the Open-End Winding IM presented in this paper in comparison with conventional topology and other control techniques. Indeed, the OEWIM in conjunction with the proposed dual IMC can be a promising solution for a very large industrial application to overcome some disadvantages associated with rectifier-inverter based Induction Motor drives in the conventional topologies.

\section{Conclusions}

In the present paper the application of the Direct Torque Control on the DIMC feeding an open-end induction drive has been investigated. The simulation results show clearly the main advantages of the open-end winding induction machines in comparison with their counterpart, where their dynamic behavior performance are well improved, such as a fast response to the reference speed changes, fast torque response to the variations of load, a reduced Common-Mode Voltage and a nearly sinusoidal current waveform at the source side with a neglected phase shift referred to the power source voltage. On the other side, the use of the dual topology converter offers more flexibility in terms of the control and the switching frequency.
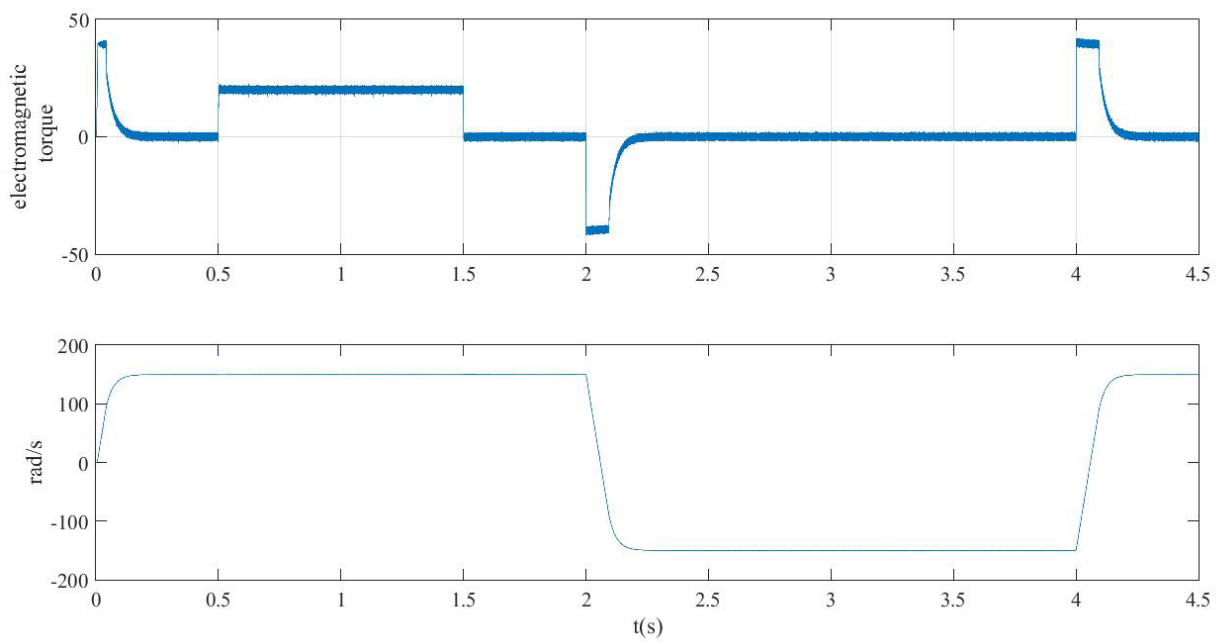

(a)
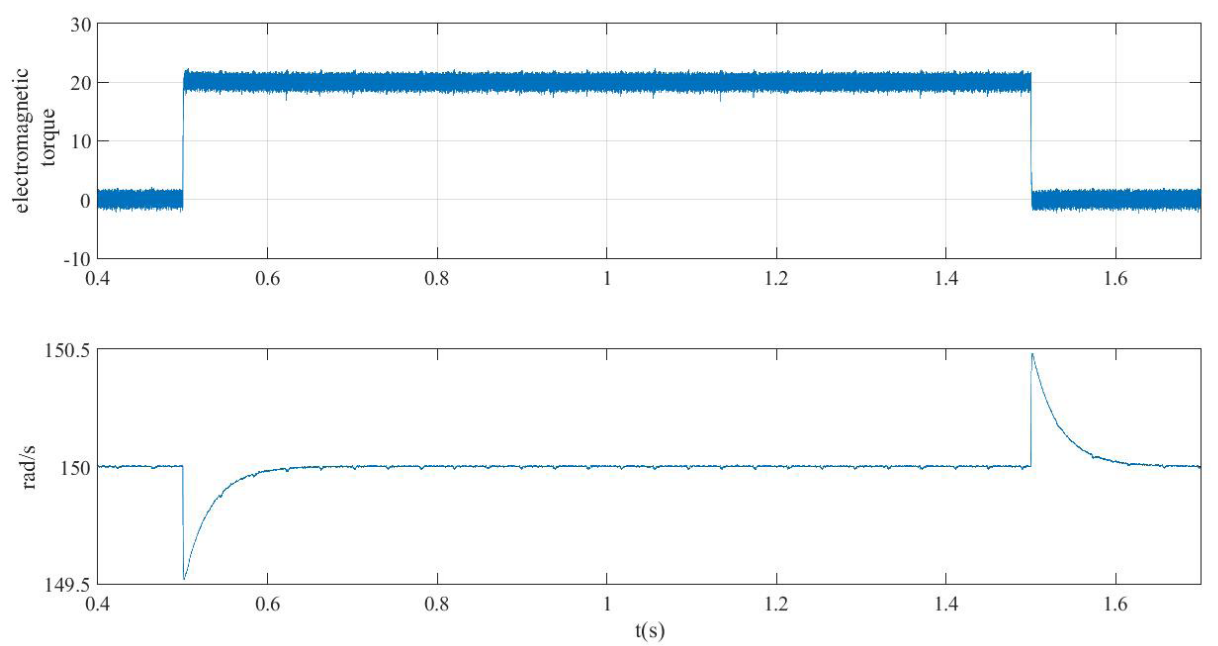

(b)

Fig. 16 (a) Change in Speed and Torque on-load condition, and (b) Zoom Change in Speed and Torque on-load condition 
Furthermore, this topology can benefit from the uncoupled control of the winding in the three-phase IM which mean that it can support the faults in a better way in comparison with the classical topologies. The obtained results in this paper prove clearly the advantages of the presented system for improving the dynamic behaviors of the IM and the better flexibility of the DIMC control. It can be concluded that the presented topology is a promising application in the industrial process where the problem of

\section{References}

[1] Erdman, J. M., Kerkman, R. J., Schlegel, D. W., Skibinski, G. L. "Effect of PWM inverters on AC motor bearing currents and shaft voltages", IEEE Transactions on Industry Applications, 32(2), pp. 250-259, 1996.

https://doi.org/10.1109/28.491472

[2] Muetze, A., Sullivan, C. R. "Simplified Design of Common-Mode Chokes for Reduction of Motor Ground Currents in Inverter Drives", IEEE Transactions on Industry Applications, 47(6), pp. 2570-2577, 2011.

https://doi.org/10.1109/TIA.2011.2170101

[3] Riedemann, J., Clare, J. C., Wheeler, P. W., Blasco-Gimenez, R., Rivera, M., Peña, R. "Open-End Winding Induction Machine Fed by a Dual-Output Indirect Matrix Converter", IEEE Transactions on Industrial Electronics, 63(7), pp. 4118-4128, 2016.

https://doi.org/10.1109/TIE.2016.2531020

[4] Kolar, J. W., Friedli, T., Rodriguez, J., Wheeler, P. W. "Review of Three-Phase PWM AC-AC Converter Topologies", IEEE Transactions on Industrial Electronics, 58(11), pp. 4988-5006, 2011. https://doi.org/10.1109/TIE.2011.2159353

[5] Riedemann, J., Peña, R., Blasco-Gimenez, R. "A resonant current control of an open-end winding induction motor fed by an indirect matrix converter", In: 2015 IEEE Applied Power Electronics Conference and Exposition (APEC), Charlotte, NC, USA, 2015, pp. 2346-2350.

https://doi.org/10.1109/APEC.2015.7104676

[6] Ahmed, S. M., Abu-Rub, H., Salam, Z. "Common-Mode Voltage Elimination in a Three-to-Five-Phase Dual Matrix Converter Feeding a Five-Phase Open-End Drive Using Space-Vector Modulation Technique", IEEE Transactions on Industrial Electronics, 62(10), pp. 6051-6063, 2015.

https://doi.org/10.1109/TIE.2015.2420038

[7] von Jauanne, A., Zhang, H. "A dual-bridge inverter approach to eliminating common-mode voltages and bearing and leakage currents", IEEE Transactions on Power Electronics, 14(1), pp. 43-48, 1999.

https://doi.org/10.1109/63.737591

[8] Surya Prakash, M. N., Srinivas, S. "Field oriented control of an open end winding induction machine with zero common mode voltage", In: 2017 National Power Electronics Conference (NPEC), Pune, India, 2017, pp. 352-357.

https://doi.org/10.1109/NPEC.2017.8310484

[9] Takahashi, I., Noguchi, T. "A New Quick-Response and High Efficiency Control Strategy of an Induction Motor", IEEE Transactions on Industry Applications, IA-22(5), pp. 820-827, 1986. https://doi.org/10.1109/TIA.1986.4504799 immediate maintenance is delicate or even difficult and the CMV is presenting a serious problem due to birth of a current circulation in the IM stator case, mainly in the bearings. As a perspective, the multi-level matrix converter can be used to give more flexibility to the control of such topology for improve the quality of absorbed power from the power source and delivered power to the load and finally to ensure a fault tolerant system in heavy industrial applications.

[10] Satheesh, G., Reddy, T. B., Babu, C. S. "DTC of Open End Winding Induction Motor fed by two space-vector-modulated inverters", In: 2011 Annual IEEE India Conference, Hyderabad, India, 2011, pp. 1-6.

https://doi.org/10.1109/INDCON.2011.6139579

[11] Matteini, M. "Control Techniques for Matrix Converter Adjustable Speed Drives, PhD Thesis, University of Bologna, 2001. [online] Available at: http://www.die.ing.unibo.it/dottorato_it/Matteini/ Matteini_PhD_part1.pdf [Accessed: 25 November 2020]

[12] Riedemann, J., Peña, R., Cárdenas, R., Clare, J., Wheeler, P., BlascoGimenez, R. "Control strategy of a dual-inverter system for an openend winding induction machine based on indirect matrix converter", In: 2014 16th European Conference on Power Electronics and Applications, Lappeenranta, Finnland, 2014, pp. 1-8. https://doi.org/10.1109/EPE.2014.6910997

[13] Kumar, D., Wheeler, P., Clare, J., Kim, T.-W. "Multi-motor drive system based on a two-stage direct power conversion topology for aerospace applications", In: 4th IET Conference on Power Electronics, Machines and Drives (PEMD 2008), York, UK, 2008, pp. 607-610. https://oi.org/10.1049/cp:20080593

[14] Abu-Rub, H., Iqbal, A., Guzinski, J. "High Performance Control of AC Drives with MATLAB/Simulink Models", John Wiley \& Sons, Inc., Chichester, UK, 2012. https://doi.org/10.1002/9781119969242

[15] Li, Y., Liu, W. "A Novel Direct Torque Control Method for Induction Motor Drive System Fed by Two-stage Matrix Converter with Strong Robustness for Input Voltage", In: 2007 2nd IEEE Conference on Industrial Electronics and Applications, Harbin, China, 2007, pp. 698-702. https://doi.org/10.1109/ICIEA.2007.4318496

[16] Faraji, V., Aghasi, M., Khaburi, D. A., Kalantar, M. "Direct torque control with improved switching for induction motor drive system fed by indirect matrix converter", In: National Conference on Electrical, Electronics and Computer Engineering, Bursa, Turkey, 2010, pp. 309-314. [online] Available at: https://ieeexplore.ieee.org/ document/5698221 [Accessed: 25 November 2020]

[17] Huber, L., Borojevic, D. "Space vector modulated three-phase to three-phase matrix converter with input power factor correction", IEEE Transactions on Industry Applications, 31(6), pp. 1234-1246, 1995.

https://doi.org/10.1109/28.475693 
[18] Sunter, S., Clare, J. C. "A true four quadrant matrix converter induction motor drive with servo performance", In: PESC Record. 27th Annual IEEE Power Electronics Specialists Conference, Baveno, Italy, 1, 1996, pp. 146-151.

https://doi.org/10.1109/PESC.1996.548573

[19] Beladel, A., Kouzou, A., Hafaifa, A., Mahi, D., Sünter, S. "ThreePhase Open-End Load supplied by a Dual AC-AC Converter based on Optimum-Amplitude Venturini Method", Electrotehnica, Electronica, Automatica (EEA),66(3), pp. 35-42, 2018. [onine] Available at: http://www.eea-journal.ro/ro/d/5/p/EEA66_3_5 [Accessed: 25 November 2020]

[20] Hava, A. M., Ün, E. "Performance Analysis of Reduced CommonMode Voltage PWM Methods and Comparison With Standard PWM Methods for Three-Phase Voltage-Source Inverters", IEEE Transactions on Power Electronics, 24(1), pp. 241-252, 2009. https://doi.org/10.1109/TPEL.2008.2005719

[21] Sünter, S., Altun, H., Clare, J. C. "A Control Technique for Compensating the Effects of Input Voltage Variations on Matrix Converter Modulation Algorithms", Electric Power Components and Systems, 30(8), pp. 807-822, 2002.

https://oi.org/10.1080/15325000290085037
[22] Lee, K.-B., Blaabjerg, F. "An Improved DTC-SVM Method for Sensorless Matrix Converter Drives Using an Overmodulation Strategy and a Simple Nonlinearity Compensation", IEEE Transactions on Industrial Electronics, 54(6), pp. 3155-3166, 2007. https://doi.org/10.1109/TIE.2007.905914

[23] Buja, G. S., Kazmierkowski, M. P. "Direct torque control of PWM inverter-fed AC motors - a survey", IEEE Transactions on Industrial Electronics, 51(4), pp. 744-757, 2004. https://doi.org/10.1109/TIE.2004.831717

[24] Benachour, A., Berkouk, E. M., Mahmoudi, M. O. "A New Direct Torque Control of Induction Machine Fed by Indirect Matrix Converter", Revue Roumaine des Sciences Techniques - Série Électrotechnique et Énergétique, 62(1), pp. 25-30, 2017. [online] Available at: http://revue.elth.pub.ro/upload/82006305_ABenachour_ RRST_1_2017_pp_25-30.pdf [Accessed: 25 November 2020]

[25] Akagi, H., Shimizu, T. "Attenuation of Conducted EMI Emissions From an Inverter-Driven Motor", IEEE Transactions on Power Electronics, 23(1), pp. 282-290, 2008. https://doi.org/10.1109/TPEL.2007.911878 